
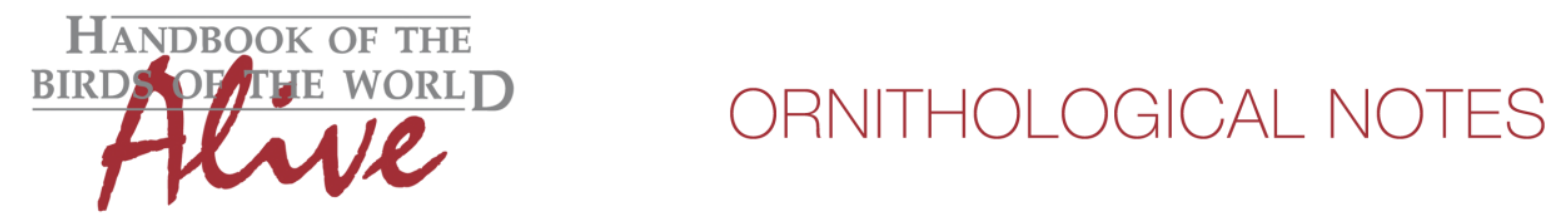

\title{
Notes on the vocalizations of Golden-faced Tyrannulet (Zimmerius chrysops)
}

Peter Boesman

In the following we briefly analyze and compare voice of the different races of Golden-faced Tyrannulet (Zimmerius chrysops). We also try to quantify the extent of any vocal differences using the criteria proposed by Tobias et al. (2010), as a support for taxonomic review. We have made use of sound recordings available on-line from Xeno Canto (XC).

In the last decade there has been a lot of discussion about taxonomy of this group of taxa, see e.g.

http://www.museum.Isu.edu/ Remsen/SACCprop363.htm

http://www.museum.Isu.edu/ Remsen/SACCprop173.htm

While it was clear that both vocal analysis and DNA analysis were needed for a better judgment, surprisingly only the latter has been done (Rheindt et al. 2008).

Also, the particular case of birds in North Peru showing morphological characters of $Z$. chrysops but voice of $Z$. viridiflavus received attention, and DNA analysis showed these birds belong to viridiflavus (Rheindt et al. 2014). This not only 'solves' this case, but is also an indirect indicator that voice in Zimmerius tyrannulets is a particularly important indicator for genetic divergence (rather than morphology).

In previous taxonomic discussions, voice differences exclusively referred to day-time call notes. I have therefore limited the quantified analysis to these calls.

The dawn song is quite different, and very similar to other members of the genus. Few samples exist however, in the dawn chorus typically of mediocre quality, and there seems to be quite some variability at first sight. While there may be interesting information in here as well, I did not tackle these in this brief analysis.

When comparing the day-time call note it was clear that seven distinct groups exist, with very little variability within groups. At most, some characters were more or less emphasized depending on the level of excitement of the bird (Fig 1). 

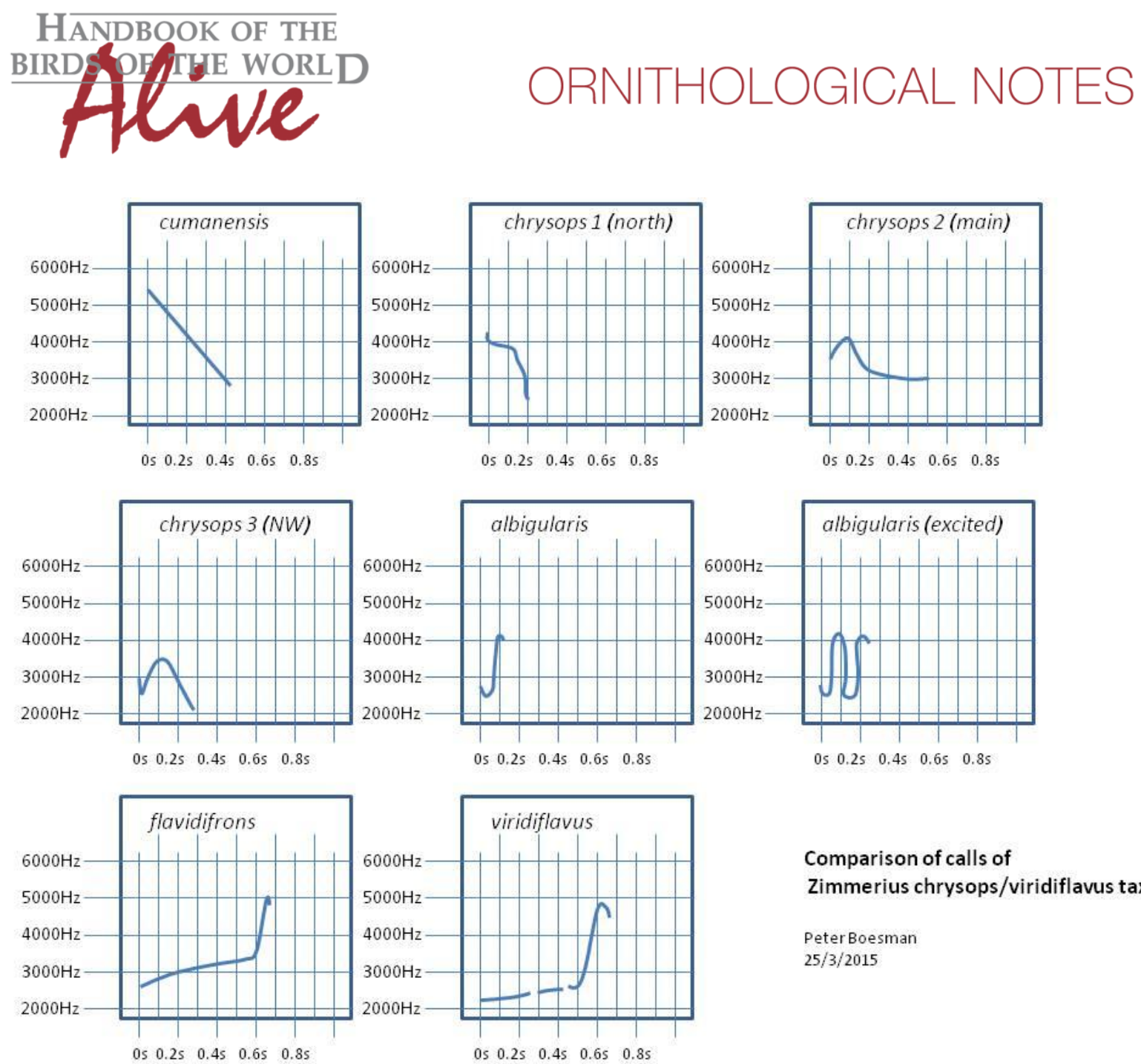

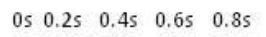

Comparison of calls of Zimmerius chrysops/viridiflavus taxa

PeterBoesman $25 / 3 / 2015$

Figure 1: A schematic comparison of day-time call notes for seven distinct groups

These groups are the following:

Coopman's group (cumanensis): Day-time call is a strident straight descending whistle (no harmonics), maximum amplitude in middle.

Golden-faced Tyrannulet group 1 of Venezuelan Andes and Perija region: Day-time call is a short, descending note (with harmonics), maximum amplitude in first half.

Golden-faced Tyrannulet group 2 Andes Colombia and Ecuador: Day-time call is a plaintive (initially up and down) descending whistle with flat-pitched ending (no harmonics), maximum amplitude after $1 / 4$ of note length.

Golden-faced Tyrannulet group 3 W Andes in Colombia: Day-time call is a short overslurred whistle (initially down and up, with harmonics), maximum amplitude in middle.

Choco Tyrannulet (albigularis): Day-time call is a short whistle ending with an emphasized rise (with ups and downs, with harmonics), maximum amplitude at $3 / 4$ of note length.

Loja Tyrannulet (flavidifrons): Day-time call is a long whistle first rising slowly than sharply (with harmonics), with maximum amplitude at end.

Peruvian Tyrannulet (viridiflavus): Day-time call is a two or three-note whistle, first ones subdued and hardly rising, the last one rising sharply and emphasized), with maximum amplitude at end. 

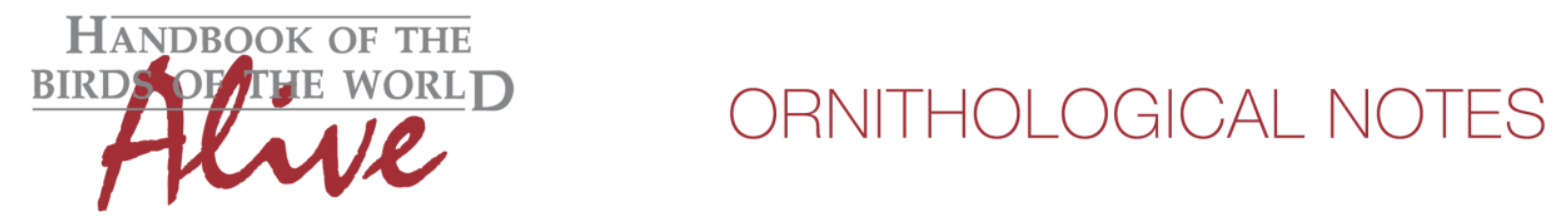

The clear difference between Z.c.chrysops group 1 and group 2 seems to coincide with the gap already drawn by Rheindt et al. (2008). Interestingly, as Z. chrysops is a typical foothill bird, the gap is not between Merida and Tachira in Venezuela, but further south.

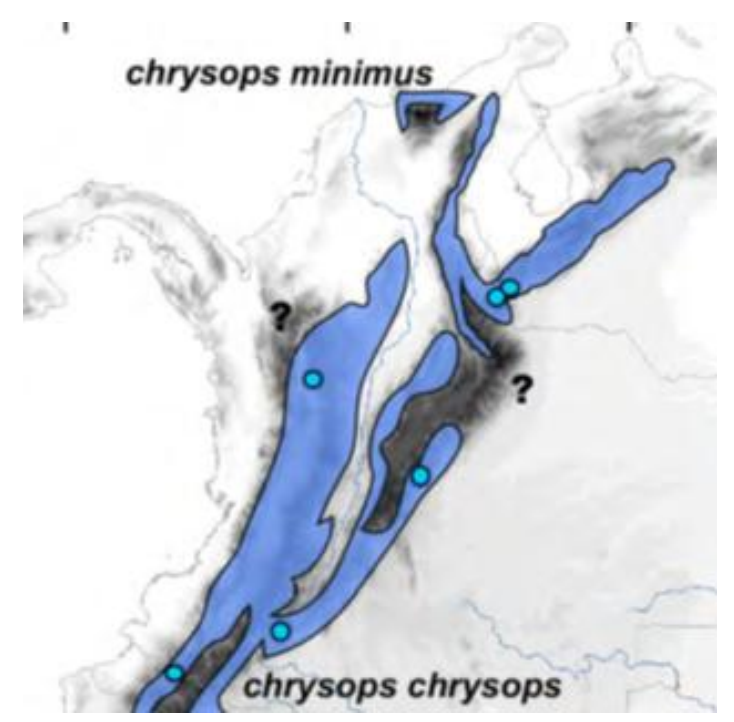

Unfortunately we don't have the voice of minimus, so we can't check if its voice pertains to group 1 or not.

Rheindt et al. (2008) did not identify the population of the western Andes in Colombia as a separate group (there were no samples of them in the study), and could thus be a cryptic taxon. A word of caution however: we have few samples of GF3.

We defined a number of relevant parameters, realized measurements, calculated effect sizes and related scores (Table 1 ).

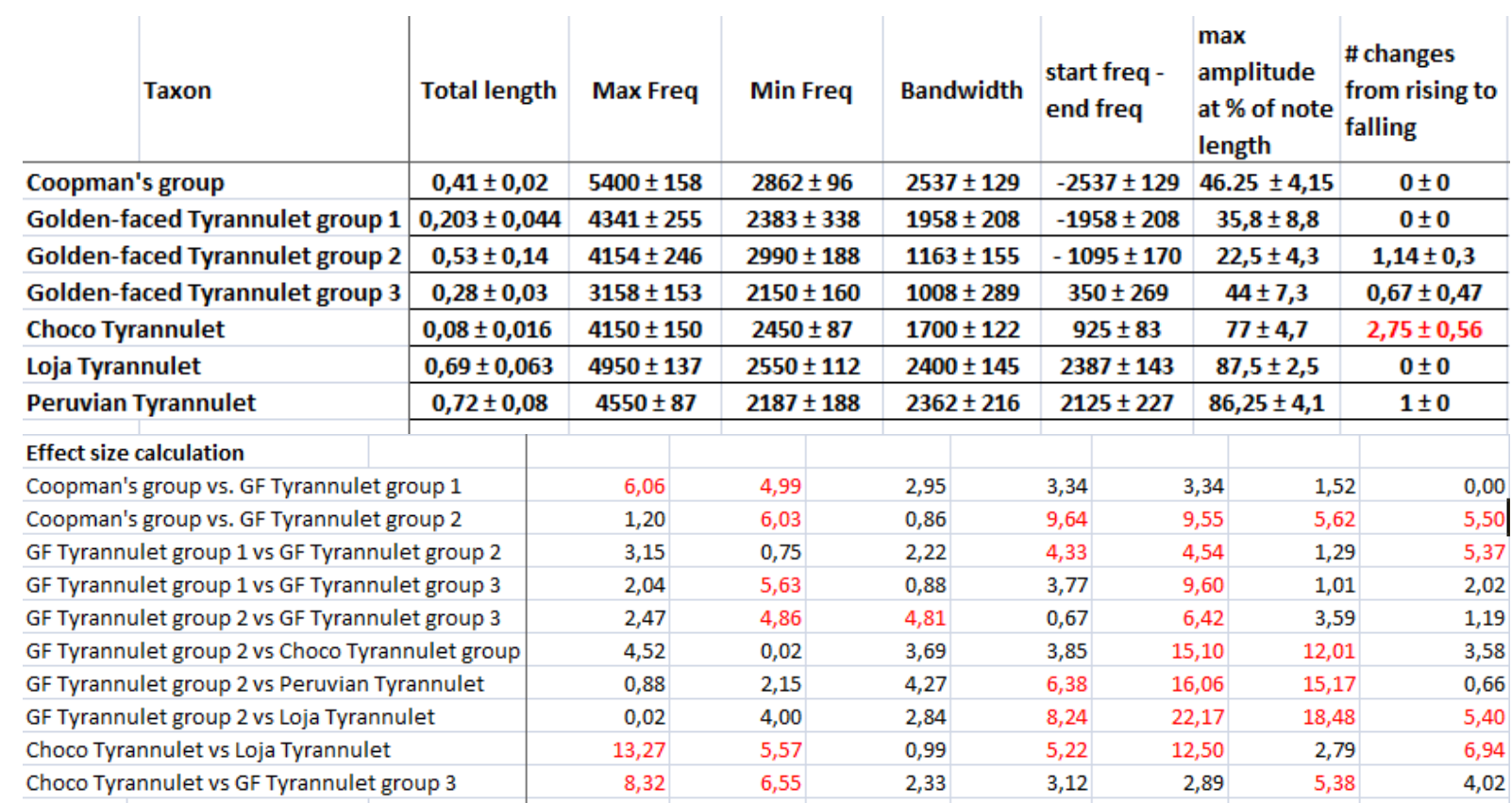

Table 1: measurements of basic sound parameters (Average \pm SD) and Effect sizes 

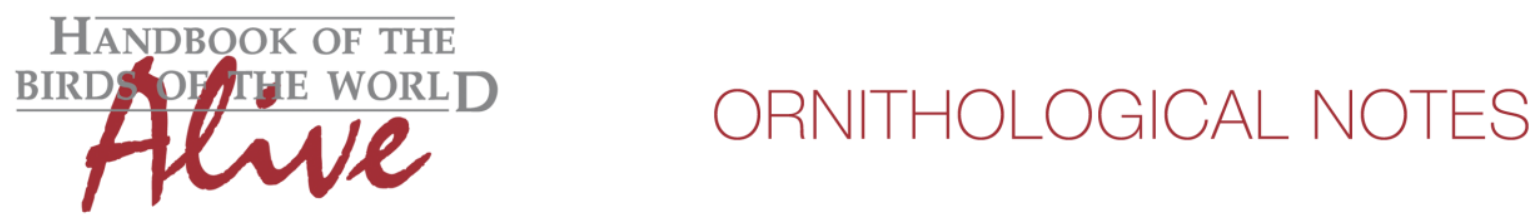

We have presented the results on the following map:

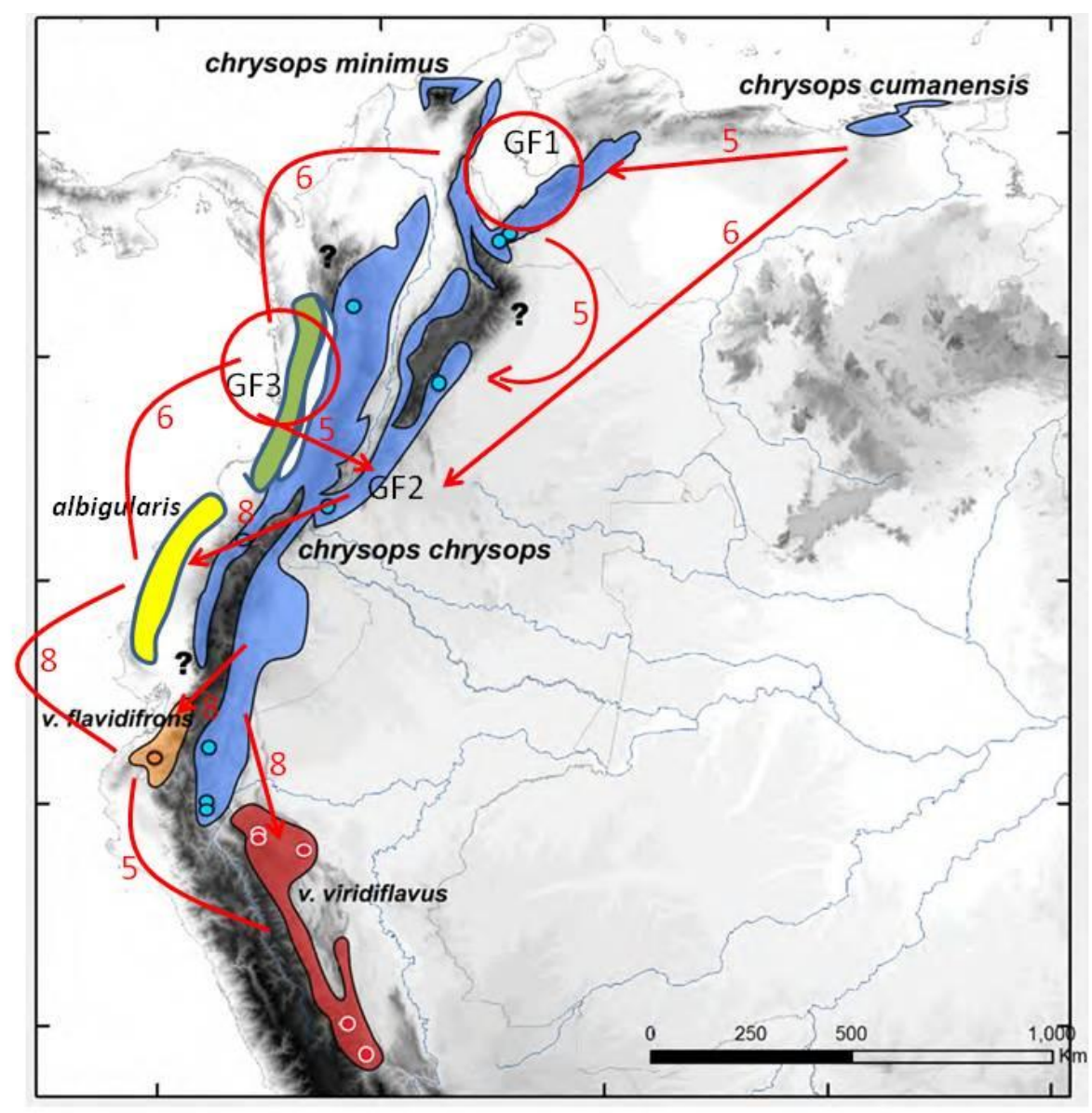

\section{Analysis of}

Z. Chrysops

Scores between

Groups

PeterBoesman

$25 / 03 / 2015$

It is clear from above analysis that the taxa flavidifrons/viridiflavus differ from all others in a high score of 8 . Between them, there is however only a single difference leading to a score of 5 (basically the difference between the 1 note call and 2-3 note call, all other characteristics being very similar). Choco Tyrannulet (albigularis) is also standing apart from flavidifrons and chrysops. Within the remaining chrysops/minimus/cumanensis cluster there are 3 clearly different voice groups, and all have differences among them scored 5 or 6.

Vocal differences in day-time call can thus be summarized as follows:

Zimmerius (chrysops) cumanensis: a strident straight descending pure whistle over a broad frequency range reaching its maximum amplitude in the middle.

Zimmerius chrysops of the Venezuelan Andes and Perija mountains: a short, descending note with harmonics, reaching its maximum amplitude in the first half of the note length. Bandwidth, lack of changes in slope and note length are main differences with chrysops further south.

Zimmerius chrysops of the Central and Eastern Andes of Colombia and Ecuador and extreme N Peru: a plaintive (initially up and down) descending whistle with flat-pitched ending, maximum amplitude after $1 / 4$ of note length. 

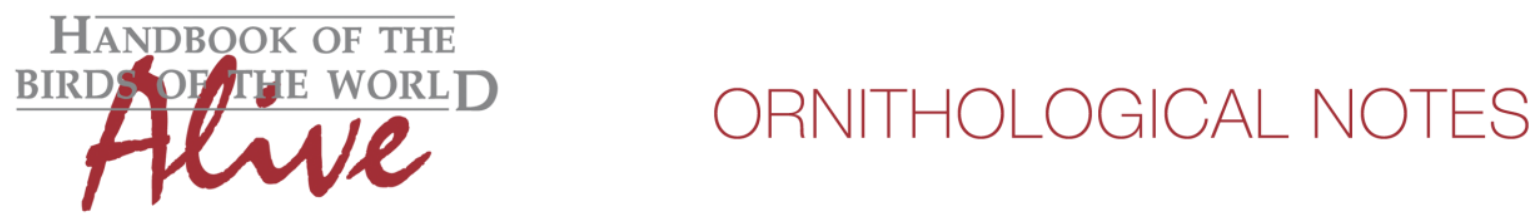

Zimmerius chrysops of Western Andes in Colombia: a short overslurred whistle (initially down and up, with harmonics), maximum amplitude in middle.

Zimmerius albigularis: a short whistle ending with an emphasized rise (with ups and downs, with harmonics), maximum amplitude at $3 / 4$ of note length.

Zimmerius (?) flavidifrons: a long whistle first rising slowly than sharply (with harmonics), with maximum amplitude at end.

Zimmerius viridiflavus: a two or three-note whistle, first ones subdued and hardly rising, the last one rising sharply and emphasized), with maximum amplitude at end.

This note was finalized on 25th March 2015, using sound recordings available on-line at that moment. We would like to thank in particular the many sound recordists who placed their recordings for this species on XC.

\section{References}

Rheindt, F. E., Cuervo, A.M. \& Brumfield, R.T. (2008). Rampant polyphyly indicates cryptic diversity in a clade of Neotropical flycatchers (Aves: Tyrannidae). Biological Journal of the Linnean Society, 108, 889-900.

Rheindt, F. E., Fujita, M. K., Wilton, P. R., and S. V. Edwards. (2014). Introgression and Phenotypic Assimilation in Zimmerius Flycatchers (Tyrannidae): Population Genetic and Phylogenetic Inferences from Genome-Wide SNPs. Systematic Biology doi: $10.1093 /$ sysbio/syt070.

Tobias, J.A., Seddon, N., Spottiswoode, C.N., Pilgrim, J.D., Fishpool, L.D.C. \& Collar, N.J. (2010). Quantitative criteria for species delimitation. Ibis 152(4): 724-746.

\section{Recommended citation}

Boesman, P. (2016). Notes on the vocalizations of Golden-faced Tyrannulet (Zimmerius chrysops). HBW Alive Ornithological Note 128. In: Handbook of the Birds of the World Alive. Lynx Edicions, Barcelona. (retrieved from http://www.hbw.com/node/932051 on 5 August 2016). 